\title{
EDUCATING MIDDLE AND HIGH SCHOOL STUDENTS IN SPACE OPERATIONS: THE SIMULATION APPROACH
}

\author{
Mansooreh Mollaghasemi \\ Michael Georgiopoulos \\ 4000 Central Florida Blvd. \\ University of Central Florida \\ Orlando, Fl 32816, U.S.A \\ Dayana Cope \\ 12565 Research Parkway, Suite 300 \\ Productivity Apex, Inc. \\ Orlando, FL 32826, U.S.A.
}

\author{
Anne Donnelly \\ 205B PS \& T \\ Particle Engineering Research Center \\ University of Florida \\ Gainesville, FL 32611, U.S.A.
}

Martin Steele

YA-D6

Kennedy Space Center

KSC, FL 32899, U.S.A.

\begin{abstract}
This paper describes a proposed pilot educational program to teach middle and high school students the space shuttle processing operations. This pilot program involves a partnership of two Universities (University of Central Florida and University of Florida), a small business (Productivity Apex), and three middle/high schools in the Florida area.

Our proposed pilot program is an innovative approach designed to teach students about the complexities of space vehicle processing through a simulation environment. Through the many planned activities that we propose to achieve our goal, we will be able to introduce middle and high school students to aerospace operations, excite them about space education, and enthusiastically engage them in science and technology related projects. The ultimate objective of this effort is to motivate middle and high school students to pursue careers in Science, Technology, Engineering, and Math (STEM) fields.
\end{abstract}

\section{INTRODUCTION}

Spaceport operations require a workforce with specialized skills and knowledge that are generally not directly addressed in today's educational programs. Continued development and expansion of this knowledge domain and skill base is critical to the sustained presence and growth of the space program. Moreover, there is a growing need to create incentives for young people to have interest in becoming part of the space operations work force to replace experienced workers who are retiring.
We propose the development of a stand-alone instructional package (module) for use by middle and high schools. This module can be integrated into a variety of classes such as physics and earth science. The overall goal of this project is to both increase middle/high school students interest in pursuing careers in science and engineering and to create understanding and incentives for careers in spaceport operations. A survey of scientists determined that early adolescence was a key time when these researchers chose a scientific career, so this is a critical age to affect career choices (Fox and Stephan 2001). Age-appropriate, cognitive goals for the module pertinent to both the middle and high school levels will be identified in collaboration with the teachers on the educational materials development team.

Specifically, we will use a simulation-based software called GEM-FLO (Generic Simulation Environment For Modeling Future Launch Operations), which was developed through a joint effort of NASA/KSC and Productivity Apex, Inc. GEM-FLO is a generic simulation modeling environment that is used to model any launch vehicle architecture ranging from single stage to multi stage and from all reusable to all expendable component (Mollaghasemi, et al 2002).

In this environment, the user provides vehicle and processing inputs, such as the number and type of flight hardware elements (FHEs), processing times, probabililties of events such as scrubs or landing in California, through a user friendly graphical user interface (GUI). A simulation model is then automatically generated so that it can provide an assessment of system capability in terms of flight rate, resource utilization, cost, and turnaround time. GEM-FLO 
can be used for evaluation of the current shuttle or new and evolving spaceport operations concepts needed to support current and next generation space launch vehicles. Using this software environment, students can learn about the various components of Reusable Launch Vehicles (RLVs), such as orbiter, booster, their requirements for processing (e.g., processing facilities, integration facilities, launch pad), and the interactions among them (e.g., the boosters need to be stacked before an external tank and an orbiter are mated to them). This will provide students not only with opportunities to learn about spaceport operations but also with general systems engineering principles through formulation of experiments and trade studies. For example, students will learn design of experiments to determine what input factors contribute to increasing the flight rate for the shuttle. Or they can reduce the time required for processing boosters to examine its impact on turnaround time. These experiments will provide students with several important skills, such as: (1) through formal introduction of spaceport operations, they will learn about the operations required to process a space vehicle and (2) in order to be able to run the software and interpret the results, students will be exposed to statistics, simulation modeling and analysis, and design of experiments. Interactive computerbased simulations provide a number of educational benefits. Learners are motivated and challenged, it allows students to manipulate variables, it helps the learner identify cause and effect relationships, and it offers an option to experience a system that would otherwise not be available to the student (Zacharia 2003).

\section{TECHNICAL APPROACH}

The proposed pilot effort has a number of objectives:

Objective 1: Produce educational materials related to simulation, modeling, and experimental design that support, and illustrate the functionality of GEM-FLO, a simulation software used extensively by NASA,

Objective 2: Deliver these educational materials to the designated middle/high schools using inquiry-based, and collaborative learning techniques; assess/evaluate the impact of this educational delivery, and

Objective 3: Disseminate these materials to educational conferences, and pursue appropriate avenues of external funding. The accomplishment of these objectives will be achieved by completing a number of tasks that are identified.

\subsection{Modifications of GEM-FLO Software (Task 1)}

In order to make the GEM-FLO software more intuitive to the students, we first need to enhance it with visualization capabilities. GEM-FLO will be appropriately modified to include run-time animation features. By observing the animation during a simulation run, students will get a visual representation of space operation and thus they will be able to better appreciate the consequences of their vehicle design on vehicle turn-around time and cost. For example, by observing the animation, students can visually identify what operations are the bottlenecks in the system. By improving these operations (through the addition of more resources or the reduction of their processing time), students can increase their system throughput or reduce production cycle times. In addition, animation serves as an important tool when validating a simulation model. By carefully observing the model animation, students can identify areas of their design that may be causing infeasible solutions.

Figure 1 provides a snapshot of the proposed animation. The animation will provide students with a snapshot of what is occurring at any given time in the simulation. For example in Figure 1, one shuttle vehicle is being processed in the launch pad, while two other shuttles are being integrated in the Integration Facilities. An orbiter is also being processed in one of the Processing Facilities. The facilities that are not being used can be seen with gray shading. For example, only one of the three available processing facilities is in use while the other two are in idle status. Furthermore, important statistics on the total number of launches, number of loss of vehicle events, and utilization of various facilities can be monitored from the animation. The task of animating a generic simulation model, such as GEM-FLO, requires considerably more effort than animating a specific simulation model. In a generic model, the number of facilities, types of entities and resources depend on the scenario being modeled. Therefore, when modeling a generic model, these animation factors become variables. For any given scenario, the animation could look totally different than the snapshot in Figure 1. To accomplish this, GEM-FLO will be enhanced by incorporating dynamic resource and entity animation based on variables and picture libraries. The middle/high school student can choose from a specific library of entity pictures that will represent the orbiter and/or other flight hardware elements to be modeled. The number of facilities and resources will be animated based on the inputs made by the students through the graphical user interface.

Finally, GEM-FLO will be enhanced to provide users with error messages if they design an infeasible vehicle. For example, if an Orbital Space Plane is selected without an expendable booster component, GEM-FLO will output an error. This will allow students to learn about space vehicle design by identifying the necessary elements to launch a vehicle to space.

\subsection{Development of Educational Materials (Task 2)}

All teaching materials will be developed by a curriculum team consisting of scientists, graduate students and middle/high school teachers to ensure that they are developed in an age appropriate way and to align them with appli- 


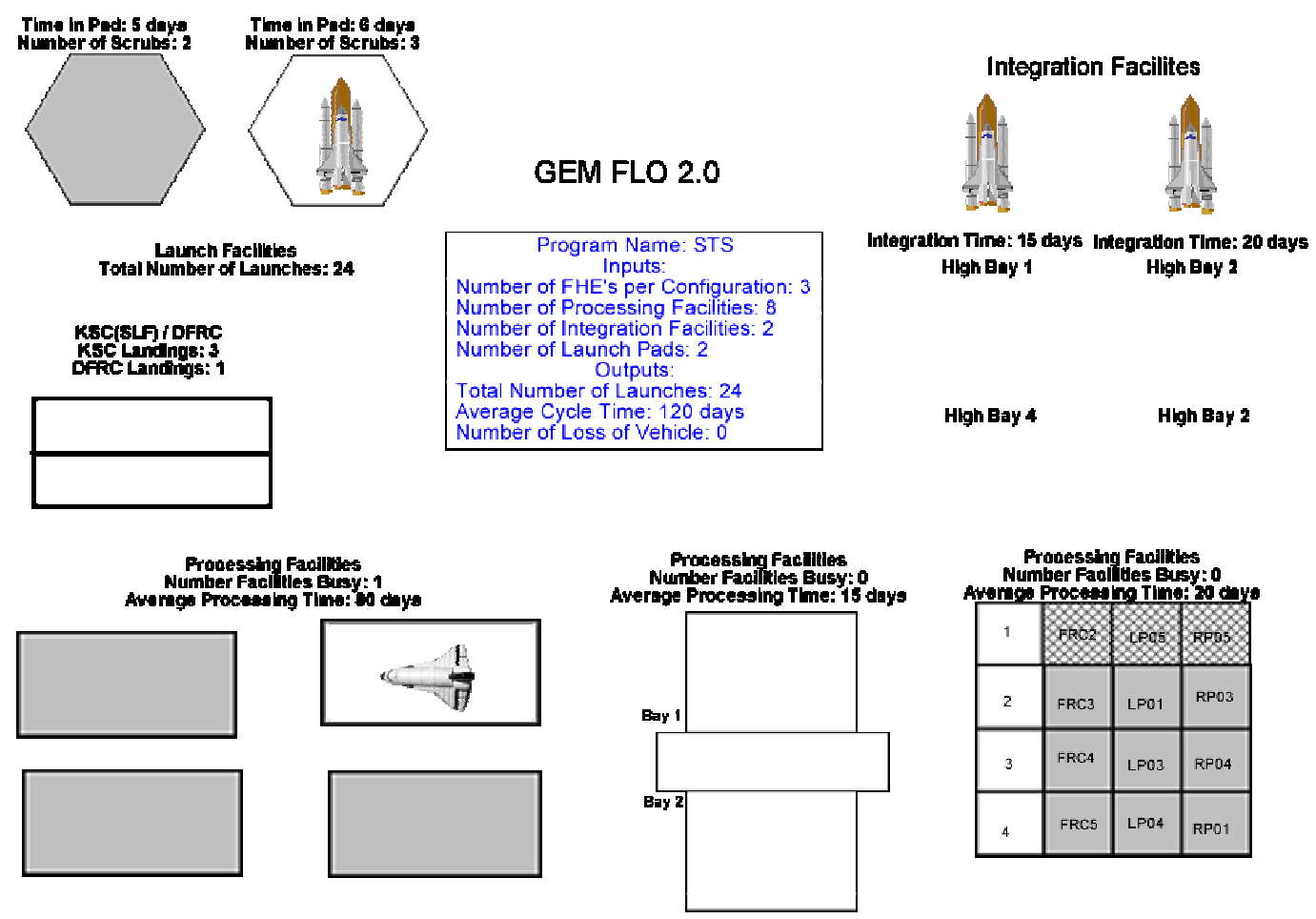

Figure 1: Snapshot of the Proposed Animation for the GEM-FLO Software

cable State Education Standards. These educational materials will be multidisciplinary in nature, integrating mathematics, science, and engineering concepts that will make it useful across a variety of disciplines. The purpose of these materials is to enhance science and math classes through the addition of an inquiry-based module and to educate students on the operations of a spaceport.

This educational material will be used to first teach students the various components of space vehicle processing such as normal ground processing, vehicle integration, launch flow, depot maintenance, etc. Macro level processes will be presented in this phase of the project. These processes along with their interactions are modeled in GEMFLO simulation software to provide a venue for understanding the complexities of vehicle operations. In order to enable students to intelligently use the GEM-FLO simulation software for understanding the nature and intricacies of aerospace operations, they will be introduced to simulation modeling and analysis techniques. To accomplish that, they will first be exposed to basic statistical concepts. Various games will be used to convey these concepts. For example, simple experiments will be conducted ranging from tossing a coin, rolling a die, to collecting data on student service times at their school cafeteria to show them how to build a distribution of the service time at lunch. Once these simple statistical concepts are explained, we will provide an introduction to modeling and simulation. We will teach them about basic simulation concepts such as entities, resources, queues, event calendars, simulation inputs and outputs processes, etc., using, once more, simple examples such as the model of school cafeteria serving students. After they have been introduced to the basics of space operations as well as statistics and simulation, we will use GEM-FLO to teach them how to evaluate various space vehicle designs using simulation. For instance, the students can experiment with the number of available orbiters to determine its impact on the number of flights per year as well as annual operations cost. Or they can contrast the design of the Orbital Space Plane (OSP) with the existing shuttle to determine how this vehicle (OSP) impacts the number of missions flown and cost of the program. Through the harmonious interplay of GEM-FLO software and the associated scientific concepts that this software is built upon, the students will get the opportunity to learn and appreciate NASA operations as well as the basic scientific underpinnings in statistics and simulation.

The materials developed will be comprehensive and they will include preparatory materials, the actual simulation experience, and follow-up materials. This modular approach will ultimately facilitate its adoption by other classroom teachers, beyond the ones that will be involved in this pilot program.

\subsection{Training of Graduate Students/ K-12 Teachers (Task 3)}

The educational materials that are developed in Task 2 will be delivered by middle/high school teachers (8-12 teachers) that are to be assisted by graduate students. These 
teachers and graduate students will be active participants in the development of the educational materials, and will be members of the partnership team involved in this pilot program. Appropriate training of these graduate students and teachers will be beneficial in more effectively delivering these materials in the classroom environment.

The training of the graduate students and the 8-12 teachers will be multifaceted. The graduate students will participate in a weeklong workshop, conducted by the Faculty Center of Teaching and Learning (FCTL) at the University of Central Florida. Some of the objectives of this workshop are to teach the students of (a) how to apply the current research on learning in the design of instructional strategies that work in different teaching environments, (b) to understand different learning styles, and how these styles inform us about student responses to instructional strategies, (c) to develop expertise in the use of effective teaching strategies, and (d) to learn and understand classroom management strategies, amongst other skills.

The graduate students will be paired with the science teachers from one of the partner middle/high schools. This interaction will start at the beginning of the project and it will continue until the end of the project. Examples of this interaction include:

(a) attendance by the graduate student in science classes that the partner science teacher teaches; this will familiarize the graduate student with the actual classroom environment, and the teaching methods used by the science teacher;

(b) weekly interaction (outside the classroom environment) of the graduate student and partner science teacher. The objective of this interaction is for the graduate student to convey the knowledge regarding the developed software and the educational materials as they are being developed. This will give the opportunity to teachers to provide valuable information regarding the effectiveness of the developed software and associated materials in the school classroom environment;

(c) attendance of the 1-day Spring Teacher workshop to solidify the education of the schoolteachers on the software and educational materials that have been developed. The purpose of the workshop is to emphasize once more the material developed, prior to its delivery to the classroom environment;

(d) attendance to the 1-day Summer Teacher Workshop to reinforce, again, the concepts discussed in the spring workshop, after the teachers and partner graduate students have had the chance to deliver the developed software and educational materials to the actual classroom environment. Part of this summer workshop will be devoted to identifying the lessons learned from this educational experience and to propose methods to improve the educational content and delivery methods;

(e) frequent interaction (weekly) of the graduate students and the PIs on this team. This will enable the graduate students on this project to become knowledgeable of the scientific and technological issues associated with the creation of the software. At the same time they will appreciate the importance of the educational materials to be developed in support of the GEM-FLO software package.

\subsection{Delivery of the Educational Materials (Task 4)}

Once the materials are fully developed they will be piloted at area middle and high schools. There is an already expressed interest by the following middle/high schools in the Florida area: University High School in Orlando and Buchholz High School and Howard Bishop Middle School in Gainesville. Teachers from this schools will be involved in the development and delivery of the proposed educational materials, and they are part of the partnership team that we have put together to carry through this pilot program.

The National Science Standards developed by the National Research Council began with a Call to Action that called for the need of a new way of teaching science - one that reflects the way science is delivered, by emphasizing inquiry. Three categories of skills that students need are identified: 1) the principles and concepts of science, 2) the reasoning and procedural skills of scientists, and 3) an understanding that science is a human endeavor. To master these skills students must have experiences that allow them to devise and carry out investigations that test their ideas (National Research Council 2000). This inquiry-based approach to science education is consistent with the findings reported in How People Learn, a report by the NRC published in 1999 (Bransford 1999). This report emphasized that learning is more than a collection of facts and that students need the skills that are incorporated into the NRC Standards (Bransford 1999). These National Standards have influenced the development of State level Standards, and this inquiry-based approach to science learning is now a fundamental part of the Florida State Standards.

The pilot project described in this paper would result in a high quality module that incorporates all of these skills. In an inquiry-based environment, students must understand fundamental concepts of math and science to comprehend the functionality of the simulation software (GEM-FLO), in order to provide inputs to the software (such number of FHEs, processing times, etc.), and based on the outputs of the software (such as flight rates, resource utilization, etc.) they could analyze and interpret the effect of their input choices. Since this is a software that is currently in use by NASA, the students will gain first-hand knowledge of how NASA scientists work. These factors ensure that the proposed project, when fully developed, will be a valuable tool in the classroom environment across the State and beyond.

While the specific details of the delivery of the module will be developed as the team begins its work, there are several fundamentals of teaching and learning science such as inquiry that will be incorporated into the design. Technology can provide an active learning experience for students, but new technologies do not by themselves guar- 
antee learning, so it is critical that the module is carefully designed to meet the goals set by the State Standards. The program will be interactive. This will provide students with valuable feedback. It has been noted that in traditional classroom feedback is not frequent, even though it is a powerful learning tool. This program will allow students to revise and retest their ideas over and over again, an example of the most effective use of feedback (Barnsford 1999). Another important component that will be built in to the module is the use of collaborative learning groups. These groups demonstrate for the student that the pursuit of scientific knowledge is a collaborative effort, reinforces group skills and provides additional feedback to the students (Vye, et al. 1998). The development team will incorporate these and other inquiry based best practices in the design of the module.

\subsection{Assessment and Evaluation of Educational Materials (Task 5)}

We view this entire experience as a combination of curriculum development (development of the science materials and associate software to better understand space shuttle operations), and curriculum delivery, teaching of the educational material to middle and high school students.

A well developed evaluation program will be designed that will involve all stakeholders - scientists, graduate students, school teachers and their students, and others as identified. This will ensure that the materials developed meet the needs of all potential users. Methodology selected for this evaluation component will be consistent with guidelines provided in the NSF 2002 User-Friendly Handbook for Project Evaluation (Frechtling 2002)

\subsection{Dissemination Efforts (Task 6)}

Results of this pilot project will be disseminated through presentations at professional educational meetings such as the American Society of Engineering Education (ASEE). Furthermore, other forums of dissemination include the Interservice/Industry Training Simulation and Education (I/ITSEC). This conference is annually held in Orlando and it emphasizes research and education in modeling and simulation. For instance, the middle/high schools involved in this effort could have an exhibition booth at the I/ITSEC conference demonstrating through the produced software and associated educational materials the results of this experience.

Once the educational materials are developed, delivered, and assessed through this pilot project additional funding to disseminate the educational materials to other middle/high schools around the nation will be pursued. Potential funding sources for this dissemination effort include NASA and the National Science Foundation (NSF).

\section{DISCUSSION}

We have presented in this paper a pilot program involving two Universities (University of Central Florida and University of Florida), a small business (Productivity Apex), and three middle/high schools in the Florida area. The purpose of this partnership was to develop, deliver, assess, and eventually disseminate innovative educational materials for the middle to high school classroom environment.

The educational materials that were proposed to be developed relied on a powerful modeling and simulation software, developed by Productivity Apex, Inc. used by NASA to to model any launch vehicle architecture ranging from single stage to multi stage and from all reusable to all expendable components. The intention was to use this software package (appropriately modified) to teach middle and high school students scientific concepts related to stastistics, modeling, and simulation. Through this effort we anticipated that a number of middle/high school students will be motivated to pursue STEM (Science Technology Engineering and Math) college degrees.

Our partnership team is currently looking for ways to fund this pilot program. Once the pilot program is funded and its successes verified we intend to pursue additional funding to expand its usage nationwide.

\section{ACKNOWLEDGMENTS}

The author (Michael Georgiopoulos) acknowledges the partial support of the following NSF grants (CRCD grant no. 0203446 and CCLI grant no. 0341601).

\section{REFERENCES}

Bransford, J. (1999). How People Learn. National Research Council, National Academy Press, Washington, D.C.

Fox, M. F. and P.E. Stephan. (2001). Preferences, Prospects and Realities by Gender and Field. Social Studies of Science, 31/1, SSS and SAGE Publications, London.

Frechtling, J. (2002). The 2002 User Friendly Handbook for Project Evaluation. National Science Foundation, Washington, DC.

Mollaghasemi, M., M. Steele, G. Rabadi, and G. Cates. (2002).A Generic Environment for Modeling Future Launch Operations (GEM-FLO). World Automation Congress, Orlando, Florida.

National Research Council. (2000). Inquiry and the National Science Education Standards. National Academy Press, Washington D.C.

Vye, N.J., D.L.Schwartz, J.D. Bransford, B.J.Barron, L.Zech, and Cognition and Technology Group at Vanderbilt. (1998). Smart Environments that Support Monitoring, Reflection, and Revision. in Metacogni- 
tion in Educational Theory and Practice, D. Hacker, J. Dunlosky, and A. Graesser, eds., Erlbaum, Mahwah, New Jersey.

Zacharia, Z. (2003). Beliefs, Attitudes, and Intentions of Science Teachers Regarding the Educational Use of Computer Simulations and Inquiry-Based Experiments in Physics. Journal of Research in Science Teaching, Vol. 40, No. 8, pp. 792-823.

\section{AUTHOR BIOGRAPHIES}

MANSOOREH MOLLAGASEMI (Ph.D.) is a tenured Associate Professor in the Department of Industrial Engineering and Management Systems at the University of Central Florida. She is also the founder and CEO of Productivity Apex, Inc. Her area of interest is simulation modeling and analysis of complex systems, multiple criteria simulation optimization, and artificial intelligence. Her email address is<mollagha@mail.ucf.edu>.

MICHAEL GEORGIOPOULOS (Ph.D.) is a Professor at the Department of Electrical Engineering and Computer Engineering at the University of Central Florida. Dr. Georgiopoulos has worked on a number of research areas such as computer/communication networks (with emphasis on random access algorithms), spread spectrum communication networks (with emphasis on probability of error evaluation of DS and FH spread spectrum systems), and on neural networks and applications in pattern recognition, image processing, manufacturing, antennas and other application areas. His e-mail address is <michaelg@mail.ucf.edu>.

ANNE DONNELLY (Ph.D.) has served as the Associate Director for Education and Outreach for the Particle Science Engineering Research Center (PERC), an NSF Engineering Research Center since 1996. Under her PERC has effectively integrated research and education across the learning continuum. This has been accomplished through an undergraduate research program, outreach to non-Center students through an NSF Research Experience for Undergraduates program, and advanced training for graduate students through the annual Particle Science Summer School. PERC is noted for its commitment to diversity and Dr. Donnelly is the Director of the UF NSF Alliance for Graduate Education and the Professoriate Program that provides support for minority $\mathrm{PhD}$ students in science and engineering. As a former high school science teacher, Dr. Donnelly is aware of the challenges faced by teachers who wish to integrate innovative materials into the science classroom. Her e-mail address is <adonnelly@erc.ufl.edu>.

DAYANA COPE is Senior Industrial Engineer at Productivity Apex, Inc. Her expertise in process simulation and analysis has involved her in multiple simulation analysis projects in diverse industries such as aerospace, housing and theme parks. She has a B.S. in Industrial Engineering from the University of Central Florida (2000) and a M.S. in Industrial Engineering- Simulation, Modeling and Analysis from the University of Central Florida (2002). She is currently working part-time to complete a Ph.D. in Industrial Engineering from the University of Central Florida. Her email address is <dcope@productivityapex.com>.

MARTIN J. STEELE (Ph.D.) is an engineer with NASA at the Kennedy Space Center (KSC) with a wide range of experience, from shuttle and payload operations to ground systems and facilities development. He is currently leading several efforts at KSC to employ simulation modeling in the operations analysis of existing and future launch vehicles. His research interests include simulation modeling and analysis of complex systems, simulation input modeling, generic system simulations, and neural networks. His email address is <martin.j.steele@nasa.gov>. 